\title{
The Relationship Between Emotional Labor and Service Quality: The Moderating Effects of Aesthetic Labor and Aesthetic Value Combination of Supervisor-Subordinate
}

\author{
Huo-Tsan Chang ${ }^{1}$, I-Chung Liu ${ }^{1}$, Chun-Chieh Chang ${ }^{1}$, Ruey-Gwo Chung ${ }^{2}$, Tsang-Lang Liang ${ }^{2}$ \\ ${ }^{1}$ Graduate Institute of Human Resource Management, National Changhua University of Education \\ ${ }^{2}$ Hsiuping University of Science \& Technology
}

Correspondence concerning tgus article should be addressed to I-Chung Liu, Graduate institute of Human Resource Management, National Changhua University of Education, No.2, Shi-Da Road, Changhua City500, Taiwan.

\begin{abstract}
The success of industry depends on the service quality it provides for its customers. Studies show that employees' emotional labor is a crucial factor which influences service quality. However, past research on how the surface acting and deep acting of emotional labor impact staff's performance has demonstrated inconsistent results, which indicates a possible moderator variable, might exist. According to the social cognitive theory, the present study holds the view that personal behaviors can be influenced by both personal and environmental factors. Taking this notion into account, the current study is to investigate the moderating effect of aesthetic labor and aesthetic value combination of supervisor-subordinate.

The findings of the current study suggest that in a high-level aesthetic labor context, staff that employ surface acting can enhance the positive impact on service quality. Those who employ deep acting in a high-level aesthetic labor context can also help enhance the positive impact on service quality. Furthermore, the high aesthetic labor and aesthetic value combination of supervisor-subordinate can increase the positive impact of surface acting on service quality. Likewise, the high aesthetic labor and aesthetic value combination of supervisor-subordinate can further improve the positive impact of surface acting on service quality.
\end{abstract}

\section{Keywords: emotional labor, aesthetic labor, aesthetic value, service quality}

\section{Introduction}

As far as service-oriented industry is concerned, its success can be guaranteed by a crucial factor that is making sure its staff can provide top quality service since service quality influences customer satisfaction. Front-line staff is essential to the competitiveness of an organization as they represent corporate image and bring the organization and its customers together (Brotheridge \& Grandey, 2002). In the recent years, research on organizational behavior has focused on issues regarding emotional labor and emotional management of work roles, which has demonstrated emotional labor impact significantly on service quality (Barger \& Grandey, 2006). Grandey (2000) points out that surface acting refers to the act of suppressing one's real inner feelings and at the same time faking an expected emotion. Deep acting, on the other hand, means to actually change one's inner emotions so as to express appropriate emotions.

Nonetheless, the studies on the meta-analysis of emotional labor indicate inconsistent results as some suggest that the deep acting of emotional labor has a positive correlation with its impact on work performance and others, on the hand, demonstrate insignificant results. As for surface acting, some studies show it has a weak positive correlation and a negative correlation with its impact on work performance while others suggest an insignificant weak correlation (Huang, Chu, Chang \& Kuo, 2014 ; Hülsheger \& Schewe, 2011 ; Kammeyer-Mueller, Rubenstein, Long, Odio, Buckman, Zhang, \& Halvorsen-Ganepola, 2013). As it can be seen, the results of the past research on the relationship between surface or deep acting and employees' work performance are inconsistent. Therefore, the present study bases itself under the notion that a moderator variable may exist in the relationship between emotional labor strategies adopted by service staff and service quality.

According to the representation theory of aesthetics, an organization creates an environment with aesthetics by applying aesthetic elements to service space and the process of service encounter in order to bring its customers a pleasant feeling as they are simulated by the aesthetic atmosphere. In this way, the customers are more likely to show word-of-mouth behavior and to repurchase, and have a positive evaluation of the overall organizational performance (Bloemer et al., 1999; Grandey et al, 2005). From the views of the social cognitive theory, factors that influence personal behavior include environmental reasons and also personal reasons (values). The value of aesthetics refers to a person with aesthetic belief who strives to live an aesthetic life and emphasizes the importance of aesthetics. A superior's value is 
Proc. of the Fifth International Conference on Advances in Social Science, Management and Human Behaviour - SMHB 2017. Copyright @ Institute of Research Engineers and Doctors. All rights reserved. ISBN: 978-1-63248-124-5 doi: 10.15224/ 978-1-63248-124-5-40

crucial in establishing the core value of a department (Giberson, Resick \& Dickson, 2005). This value is also often regarded as essential in creating the atmosphere of a work environment. For a superior with aesthetic value, it is important to apply aesthetic elements to different service contexts to make customers feel the simulation of aesthetics. This display of aesthetics ranges from the furnishings to staff's service, making the service environment have a aesthetic feel. Hence, it is interesting to see how the compatibility of a superior's value and a subordinate's value can impact an employee. Based on the supplementary fit theory, the similarity between an employee and a work environment (i.e. direct manager's values) can help improve the employee's work performance (Muchinsky \& Monahan, 1987). Moreover, the employee would feel satisfied with the work environment (Taris \& Feij, 2000).

\section{Literature Review}

\section{The Moderating Effect of Aesthetic Labor on the Relationship between Emotional Labor and Service Quality}

Emotional labor means that while serving a customer the worker strives to adjust his/her emotions to meet the standards of the organization. Hochschild (1983) suggests that workers of emotional labor must possess the following three characteristics. First, the workers must be in contact with the public in person or through voice interaction. Next, the workers should be able to express appropriate emotions when facing the customers. Third, to a certain extent the organization constrains the workers emotionally through monitoring or setting regulations. With the development of a service-oriented society, an organization would usually adopt emotional display rules to specifically require its workers to show appropriate emotions while serving customers (Rafaeli \& Sutton, 1987; Wilk \& Moynihan, 2005). In this way, the workers would abide by the emotional display rules so as to meet the service quality expected by the organization. Henning-Thurau and colleagues (2006) define emotional display rules as the anticipated emotions and emotions that are expected to be suppressed when staffs interact with customers. When the staff express positive emotions, these emotions would lead to the positive evaluation of the service quality through infecting process (Grandey et al., 2005), which would consequently make the customers have a good impression on the organization and enhance the service quality. Staffs adopt acting strategies to create these emotional expressions which including surface acting and deep acting.

The term "aesthetics" refers to employing senses to perceive things. German philosopher, Alexander Baumgarten, argues that the significance of aesthetics is to discuss the essence of beauty and the meaning of it. It is a subdivision of philosophy, which concerns the understanding of beauty and interests, and the appreciation of art, literature and styles (Chao, 2002). In the past, western philosophers made inquiries about what beauty was. Plato once stated that "beauty is really brilliant." Being real means to be harmonious, balanced, and delightful in form. In general when we mention beauty we refer to the feelings of delight (Hs, 2009). While in the past aesthetic experience was only applied to the appreciation of artwork, it has now acquired a more generalized definition. It now stands for the personal sensory perception of beauty in any situation that can result in the feeling of pleasure.

Based on Bandura's (1977) social cognitive theory, people, behavior and environment interact. Individual behavior could be affected by personal factors such as attitudes, behavioral intentions and environmental factors. Warhurts and colleagues (2000) present the concept of aesthetic labor. They suggest that 'emotional labor' proposed by Hochschild (1983) merely emphasizes that an organization should require its employees to become workers who are full of positive emotions and overlooks employees' external expression during the actual service process. Aesthetic labor means through the concept of aesthetics an organization provides its customers with aesthetic experience during its service process. That is, the organization applies aesthetics to its service including how its staff behave, speak and dress, and its purpose is to demonstrate the aesthetics of service (Nickson et al., 2005).

For staffs that employ surface acting in an organization where an environment of aesthetic service is created and the delivery of staff's emotions is demanded, they abide by the emotional display rules of the organization to keep their job (Grandey, 2003). Hence, they would also fulfill the requirement of the organizational aesthetic service. The organization creates an aesthetic environment, makes the employees wear uniform, and provides the employees with related training courses. By doing so, the organization hopes to satisfy its staff's need of aesthetics. When individual needs are satisfied, intrinsic motivation would be enhanced (Deci \& Ryan, 1985), which would then result in higher involvement in work and higher service motivation. This type of behavior not only can increase the efficacy of the organization, but can also enhance staff's service quality and customers' overall evaluation of the organization (Grandey et al., 2005). The aesthetic service environment established by the organization is meant to provide a service encounter with aesthetic experience for the customers, to generate a delightful feel, and to result in high evaluation of the organization. For the staffs that adopt deep acting they think the aesthetic service and the service attitudes shaped by the organization aim to offer the customers a nice service experience. Hence, they feel content to work in this kind of environment. In his model of attitudes, intentions and behavior, Bagozzi's (1992) proposes that the employees, who have a positive evaluation on the work environment, would have higher work satisfaction and tend to stay in a positive mood at work. When the employees are in a positive emotional state, they are more likely to act helpful to the customers (George, 1991). The two proposed hypotheses are as follow.

H1:Aesthetic labor would strengthen the positive relationship between surface acting and service quality.

H2:Aesthetic labor would strengthen the positive relationship between deep acting and service quality.

The Moderating Effect of Aesthetic Value Combination of Supervisor-Subordinate on the Relationship between Emotional Labor and Service Quality

Based on Bandura (1977), the interaction between service staff and customers would influence the effect of 
Proc. of the Fifth International Conference on Advances in Social Science, Management and Human Behaviour - SMHB 2017. Copyright (C) Institute of Research Engineers and Doctors. All rights reserved. ISBN: 978-1-63248-124-5 doi: 10.15224/ 978-1-63248-124-5-40

service quality; however, other factors might still affect service quality (Schenider et al., 1998). In Liao and Chuang's study (2004), they suggest that the organizational environment has a direct or moderating effect on service quality. For the present-day hotel industry, it emphasizes the value of aesthetics and applies the aesthetic elements to the service situations. This makes the work environment filled with an aesthetic feel and further puts an emphasis on staff's display of aesthetic service during the service process. In this case, supervisors often play an important role in creating the atmosphere of the work environment and their personal value would shape the core value of the department (Giberson, Resick \& Dickson, 2005), which would influence staff's behavior. According to the concept of Supplement fit theory, the interaction between personal factors and environmental factors means that personal behavior would be affected by the compatibility of personal factors and environmental factors. Here, the interaction between environmental factors and personal factors is represented by supervisors' personal value. Hence, this subsection would explore how supervisors' personal value affects staff's work performance. As hotel industry emphasizes on aesthetics, the present study departs from the aspect of aesthetic value combination of supervisor-subordinate to investigate its effects on the two strategies of emotional labor and service quality. That is, the present research attempts to examine the moderating effect of aesthetic value combination of supervisor-subordinate. From the above, the present study infers the followings.

H3:The aesthetic value combination of supervisor-subordinate would strengthen the positive relationship between surface acting and service quality.
H4: The
aesthetic
value
combination
of supervisor-subordinate would strengthen the positive relationship between deep acting and service quality.

\section{Research Methods}

\section{Research Framework}

The notion of the present study is indicated in Figure 1.

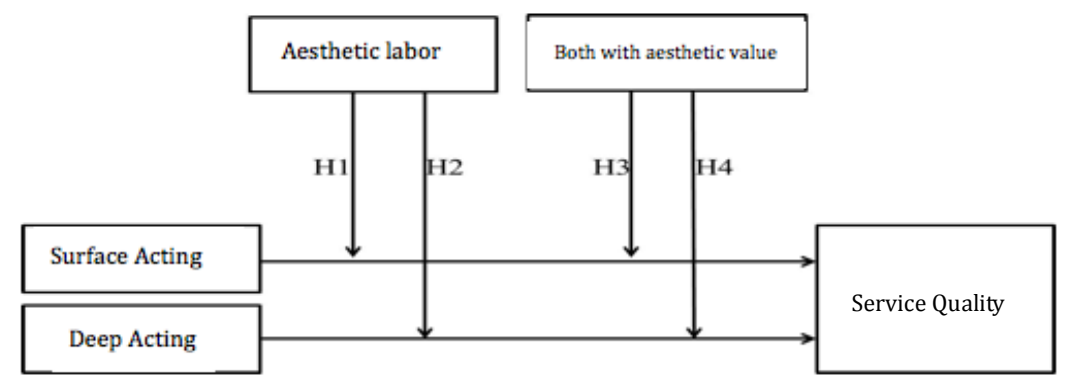

Figure. 1 Research Framework

\section{Sampling and Procedures}

The sampling population of this research was from the established tourist hotels recognized by Tourism Bureau, Ministry of Transportation and Communications. The questionnaires were distributed to the supervisors and service staff from the food and beverage departments of these hotels. In total, 50 hotels were selected and 110 supervisor-subordinate paired-comparison questionnaires had been given out (including 435 staff questionnaires and 110 supervisor questionnaires). Each supervisor is pair with 3 to 5 staffs. In the end, the number of the valid paired questionnaires was 289. The valid response rate is $66.4 \%$. Among the valid questionnaires, $69.9 \%$ of the subjects are female. $62.6 \%$ of the subjects have a university or above degree. As for the age, $50.2 \%$ of them are below 25 years old. Finally, $51.6 \%$ of the subjects have already worked one to three years.

\section{Measures}

The present study employed questionnaire investigation to collect data. In order to decrease the common method variance (CMV) bias, two questionnaires were designed - one for the supervisors and the other for the service staff (Kirkman
\& Rosen, 1999). Two questionnaires must be completed to form a pair of valid questionnaires. In the data collection process, this research matched data from different sources so as to segregate the sources (Peng, Kao \& Lin, 2006) and lower the effect of CMV on the results. Therefore, the service staff completed for sections, which were 'emotional labor', staff's personal 'aesthetic value', 'aesthetic labor perception' and basic personal information. As for the supervisors, they had to answer two sections, which were supervisors' personal 'aesthetic value and their matching staff's 'service quality'.

\section{Emotional Labor}

In Grandey's (2003) scale of emotional labor strategies, emotional labor has been divided into two aspects - five questions about surface acting and three questions about deep acting. A five-point Likert scale is applied as 1 stands for 'never' and 5 stands for 'always. The confirmatory factor analysis was first conducted to examine the reliability and validity of the scale. The results of the Cronbach's alpha analysis were .70 and .72 . The factor loading of the questions regarding the surface acting ranged from .50 to .65 . On the other hand, the factor loading of the deep acting questions ranged from .61 to .76 . The composite reliability was .70 and .74 and the average variance extracted was .32 and .48 
Proc. of the Fifth International Conference on Advances in Social Science, Management and Human Behaviour - SMHB 2017. Copyright (C) Institute of Research Engineers and Doctors. All rights reserved. ISBN: 978-1-63248-124-5 doi: 10.15224/ 978-1-63248-124-5-40

respectively.

Table 1. The Discriminant Analysis of Emotional Labor Acting Strategies

\begin{tabular}{cccccccc}
\hline Hypothesized Model & $\Delta \chi^{2}$ & $\Delta$ df & CFI & GFI & NNFI & SRMR & RMSEA \\
\hline Non-Restricted & & & .98 & .97 & .97 & .04 & .06 \\
\hline Restricted & 34 & 1 & .94 & .94 & .92 & .06 & .09 \\
\hline
\end{tabular}

Note:1.CFI = Comparative Fit Index 2.GFI = Goodness of Fit Index 3.NNFI = Non-normed Fit Index

4.SRMR = Standardized Root Mean Square Residual 5.RMSEA = Root Mean Square Error of Approximatio

\section{The Aesthetic Value Combination}

The personal value measurement proposed by Giberson and colleagues (2005) was employed in the present study. Originally, it contains ten categories of personal value, but this study has only adopted the six questions in the 'aesthetic value measurement' section. A five-point Likert scale is applied as 1 stands for 'very unimportant' and 5 stands for 'very important'. The confirmatory factor analysis was first conducted to examine the reliability and validity of the scale. The result of the Cronbach's alpha analysis was .82 . The factor loading of the questions ranged from .61 to .69. The composite reliability was .82 and the average variance extracted was .43. He and Wang (2004) suggest the notion 'fit as moderating'.

\section{Aesthetic Labor}

Research on aesthetic labor is mainly exploratory and qualitative. The present research has reviewed studies related to aesthetic labor and organized all the questions stated in the previous empirical studies. Nickson and colleagues (2005) inquired the employers and employees in hotel industry about the actual practice of aesthetic labor in the organizations. Their questions items were modified and in the end 11 aesthetic labor questions were used in the present study. A five-point Likert scale is applied as 1 stands for 'strongly disagree' and 5 stands for 'strongly agree'. The result of the Cronbach's alpha analysis was .89. As this scale was formed after the review of the literature, an exploratory factor analysis was first used to understand the factor loading of the questions. The factor loading of the questions ranged from .49 to .83, which meets the standard value of .30 or above (Hair, Anderson, Tatham \& Black, 1998). Next, the confirmatory factor analysis was then conducted to examine the reliability and validity of the scale. The composite reliability was .89 and the average variance extracted was .45 .

\section{Service Quality}

Hui and colleagues' (2003) staff service quality scale was adopted, which included nine questions regarding internal customer service and seven questions about external customer service. A five-point Likert scale is applied as 1 stands for 'strongly disagree' and 5 stands for 'strongly agree'. The result of the Cronbach's alpha analysis was .91. The factor loading of the questions ranged from .50 to .72. The composite reliability was .91 and the average variance extracted was .40 .

\section{Control Variables}

In order to control the possible moderators of other variables, the service-related literature was reviewed. As can be seen, studies usually regard sex, age, education, and years of work experience as control variables. Hence, in the present study sex, age, education, and years of work experience were the control variables so as to avoid possible moderating effects.

\section{The Confirmatory Factor Analysis}

Data was submitted to LISREL to conduct the confirmatory factor analyses of the variables, including surface acting, deep acting, aesthetic labor perception, aesthetic value and service quality. The results revealed that the goodness of fit index was up the standard as CFI $=.95, \mathrm{NFI}=.91, \mathrm{SRMR}=.07$ and RMSEA $=.07$

\section{Data Analysis}

After the data collection, data were submitted to SPSS and LISREL. First, the reliability analysis and the confirmatory factor analysis were carried out. Next, the hierarchical regression analysis was conducted to verify the hypotheses.

\section{Results and Discussion}

Research has shown inconsistent results of the relationship between staff's emotional labor and work performance, and has suggested that the situational factor could be the moderating variable. Therefore, the present study, from the aesthetic perspective, attempts to investigate whether the situation of aesthetic labor and aesthetic value could be the moderating variable between emotional labor and service quality. The results of this study have found that staff's perception of aesthetic labor and aesthetic value combination of supervisor-subordinate are the important variables that moderates with the effect of emotional labor on service quality. The findings of the present study are listed below.

\section{With high aesthetic labor, surface acting would increase the positive effect of the service quality.}

Researchers suggest that staff often employ surface acting and abide by the organizational requirements of emotional expression so as to keep their jobs, not because they sincerely would like to help the customers (Grandey, 2003). Compared with the staffs that employ deep acting, it is not certain that they could provide good service quality. When an organization added aesthetic elements to its work environment, such as the aesthetics of work space and the provision of aesthetic service courses, this would satisfy the staff's pursuit of aesthetics and consequently enhance their intrinsic 
Proc. of the Fifth International Conference on Advances in Social Science, Management and Human Behaviour - SMHB 2017. Copyright @ Institute of Research Engineers and Doctors. All rights reserved.

ISBN: 978-1-63248-124-5 doi: 10.15224/ 978-1-63248-124-5-40

motivation (Deci \& Ryan, 1985). Hence, when employees are content with their work environment, their intrinsic motivation would be increased and they would feel satisfied with their work environment, which would then result in their higher involvement in work and higher service motivation.

With high aesthetic labor, deep acting would increase the positive effect of the service quality.

Employees, who adopt deep acting, have a friendly and assiduous personality (Diefendorff et al., 2005). They would consider customers' needs from within and express sincere emotions. Employees' deep acting is an extra role behavior in the service encounter. This concept is similar to that of organizational citizenship behavior. These employees would take the initiative to understand customers' needs and help them solve their problems, which surpasses the service quality required by the organization. When an organization puts emphasis on aesthetic service, it would design related service training for its staff to realize the aesthetics of its service, and would adopt related regulations to make its staff have the aesthetic quality. These employees tend to demonstrate prosocial behavior, which could lead to higher satisfaction of the customers and the service quality (Bagozzi, 1992 ; Payne \& Webber, 2006). Furthermore, staffs with high work satisfaction are more likely to generate positive mood and emotions at work, and consequently they are more likely to act helpful to the customers (George, 1991).

\section{When the Aesthetic Value Combination of Supervisor-Subordinate is High, Surface Acting's positive Relationship with the Service Quality Could be Enhanced.}

A high aesthetic value combination of the employees, who adopt surface acting and their supervisors, could improve service quality. Staff often employ surface acting and abide by the organizational service requirements so as to keep their jobs. Recently, hotel industry has put a great emphasis on aesthetic service as the building of an aesthetic environment and the provision of relative aesthetic training and regulations have been the focuses. According to the framework of the value theory, one's value determines his/her behavior, attitudes and motivation (Meglino \& Ravlin, 1998).

From the perspective of supplementary fit theory, having similar or the same characteristics to the work environment could help enhance employees' work performance (Muchinsky \& Monahan, 1987), and would make the employees feel satisfied with and committed to the work environment (Cable \& Judge, 1996). Research has shown that when an employee's value is compatible with the supervisor, the work satisfaction and commitment of the employee would be higher (Meglino, Ravlin \& Adkins, 1989).

When the Aesthetic Value Combination of Supervisor-Subordinate is High, Deep Acting's Positive Relationship with the Service Quality could be Enhanced.

A high aesthetic value combination of the employees, who adopt deep acting and their supervisors, could improve service quality. Different from the surface acting employees, who abide by the organizational service requirements so as to keep their jobs, deep acting employees do not merely comply with the internal regulations of the organization during the service encounter. This not only surpasses the organizational requirements, but also increase the efficacy of the organization; as a result, the service quality and the overall evaluation of the organization would be improved (Grandey, Fisk \& Steiner, 2005). In the past years, hotel industry has put a great emphasis on aesthetic service as the building of an aesthetic environment and the provision of relative aesthetic training and regulations have been focused.

\section{Managerial Implications, Limitations and Future Studies}

\section{Managerial Implications}

Hotel Industry should strengthen aesthetic labor. As the current social environment is service-oriented, service quality is the key factor that influences the competitive advantage of an organization (Jayasundara et al., 2009). The present study has shown that the friendly and warm attitude of the service staff is beneficial to the enhancement of the service quality. It would make the customers have the aesthetic experience during the service encounter, which would result in positive evaluation of the organizational service (Bloemer et al., 1999). An organization incorporates aesthetic perspectives into its service environment to equip itself with competitiveness. The organization could teach its staff to deliver aesthetic service through pre-employment training courses such as deportment, professional hairstyle or make-up, etc. Besides, hotel industry could utilize its signature brand to form a specialized internal lecturer team and organize a complete aesthetic program to pass on the skills of aesthetic service.

Also, the present study suggests that it is crucial for the employees to have aesthetic value. As personal could be fostered through environment, a company could make its employees understand its emphasis on aesthetics through pre-employment training and job training programs. In addition, it could organize aesthetics-related courses to raise its employees' attention to aesthetics. Based on Maslow's hierarchy of needs, every individual has the need to pursue aesthetics. Whether or not a supervisor has aesthetic value is also important. Therefore, an organization must put emphasis on the training of aesthetic value for its supervisors. In this way, the aesthetic value could be conveyed and gradually establish the aesthetic value among the staff.

\section{Limitations and Future Studies}

This research inevitably involves certain limitations that should be acknowledged. First, the sampling of the present study is confined to the service staff and supervisors of the hotel industry. Therefore, the findings might not be applied to other staff in other industry. This study has decided to focus on single industry is to control the differences between industry (Seger, Inceoglu, Vloeberghs, Battram \& Henderickx, 2008). Future research could investigate how the application of aesthetics can be applied to other industry to understand its effects. Next, the staff's service quality in the present research was evaluated by the supervisors to avoid common method variance. Finally, the present study has investigated the moderating effects of the situations of the organizational 
Proc. of the Fifth International Conference on Advances in Social Science, Management and Human Behaviour - SMHB 2017. Copyright $\odot$ Institute of Research Engineers and Doctors. All rights reserved. ISBN: 978-1-63248-124-5 doi: 10.15224/ 978-1-63248-124-5-40

aesthetic labor and the aesthetic value combination of supervisor-subordinate on emotional labor and service quality.
However, more aesthetics-related variables could be examined in the future.

\section{Reference}

Aiken, L. S., \& West, S. G. (1991).Multiple regression: Testing and interpreting interactions. Newbury Park, CA: Sage.

Anderson, J. C., \&Gerbing, D.W. (1998). Structural equation modeling in practice: A review and recommended two-step approach. Psychological Bulletin, 103(3), 411-423.

Bagozzi, R. P. (1992). The self-regulation of attitudes, intentions, and behavior.Social Psychology Quarterly, 55(2), 178-204

Bandura, A. (1986). Social foundations of thought and action. Englewood Cliffs, NJ: Prentice-Hall.

Barger, P. B., \& Grandey, A. A. (2006). Service with a smile and encounter satisfaction: Emotional contagion and appraisal mechanisms. Academy of

(2005).The dimensionality and antecedents of emotional labor strategies.Journal of Vocational Behavior, 66(2), 339-357.

George, J. (1990). Personality, affect, and behavior in groups.Journal of Applied Psychology, 75(2), 107-116.

George, J. M. (1991). State or trait: Effects of positive mood on prosocial behaviors at work. Journal of Applied Psychology, 76, 299-307.

Giberson, T. R., Resick, C. J., \& Dickson, M. W. (2005). Embedding leader characteristics: An examination of homogeneity of personality and values in organizations.Journal of Applied Psychology, 90(5), 1002-1010.

Gibson, C. B., \& Birkinshaw, J. (2004). The antecedents, consequences and mediating role of organizational ambidexterity. Academy of Management Journal, 47, 209-226.

Goldman, A. (2001). The aesthetic. In Gaut, B., \& Lopes, D. M. (Eds.), Theroutledge companion to aesthetics (pp. 181-192). London: Routledge.

Gosserand, R. H., \&Diefendorff, J. M. (2005). Emotional display rules and emotional labor: the moderating role of commitment. Journal of Applied Psychology, 90(6), 1256-1264.

Grandey, A. A. (2000). Emotion regulation in the workplace: A new way to conceptualize emotional labor. Journal of Occupational Health Psychology, 5(1), 95-110.

Grandey, A. A. (2003). When "the show must go on" : Surface acting and deep acting as determinants of emotional exhaustion and peer-rated service delivery. Academy of Management, 46(1), 86-96.

Grandey, A. A., Fisk, G. M., Mattila, A. S., Jansen, K. J., \& Sideman, L. A. (2005). Is service with a smile" enough? Authenticity of positive displays during service encounters. Organizational Behavior and Human Decision Processes, 96(1), 38-55.

Grandey, A. A., Fisk, G. M., \& Steiner, D. D. (2005). Must "service with a smile" be stressful? The moderating role of personal control for American and French employees.Journal of Applied Psychology, 90(5), 839-904.

Hair, T. F., Anderson, R. E., Tatham, R. L., \& Black, W. C. (1998).Multivariate data analysis (5th ed.). UK: Prentice Hall.

Hatfield, E., Cacioppo, T. J., \& Rapson R. L. (1994).Emotional contagion. Cambridge, UK Cambridge University.

Hennig-Thurau, T., Groth, M., Paul, M., \&Gremler, D. D. (2006). Are all smiles created equal? How emotiona contagion and emotional labor affect service relationships. Journal of Marketing, 70(3), 58-73.

Hochschild, A. R. (1983). The managed heart: Commercialization of human feeling. Berkeley, CA:
Management Journal, 49(6), 1229-1238.

Biswas, M. (2009). Aesthetic labour in India: Locating and mapping the mind of the practitioners-an application of chaid algorithm. Journal of Services Research, 9(2).

Bloemer, J., De Ruyter, K. \& Wetzels, M. (1999), Linking perceived service quality and service loyalty: A multidimensional perspective, European Journal of Marketing, 33,1082-1106.

Brotheridge, Celeste M. \& Grandey, A. A. (2002) Emotional Labor and Burnout: Comparing Two Perspectives of 'People Work. Journal of Vocational Behavior, 60(2), 17-39.

Cable, D. M., \& Derue, D. S. (2002). The convergent and discriminant validity of subjective fit perceptions. Journal of Applied Psychology, 87, 875-884.

Cable, D. M., \& Judge, T. A. (1996).Person-organization University of California.

Hui, C. H., Cheng. K. \& Gan.Y. (2003). Psychological collectivism as a moderator of the impact of supervisor - subordinate personality similarity on employees service quality. Applied Psychology: An International Review, 52(2), 175-192.

Huang De Hsiung(2014). The application of Aesthetic 。 Education Research Journal , 201401(273), 31-4

Huang Dun Chun \& Chu Nai Wen \& Chang YaTing \& Kuo Wei Chen(2014)。Emotional Labor' s Cause, Results and potentional variables : Research in Meta-Analysis, Human Resource Management 14(3), 93-134。

Hülsheger, U.R., \& Schewe, A.F. (2011). On the costs and benefits of emotional labor: A Meta-Analysis of three decades of research. Journal of Occupational Health Psychology, 16(3), 361-389.

Hs Bai Chun(2009).The code of Aesthetics Economy. Taipei City : Business Week

Jayasundara, C., Ngulube, P., \&Minishi-Majanja, M. K. (2009).A theoretical model to predict customer satisfaction in relation to service quality in selected university libraries in Sri Lanka.Journal of Library and Information Science, 75(2), 179-194.

Kammeyer-Mueller, J. D., Rubenstein, A. L., Long, D. M., Odio, M. A., Buckman, B. R., Zhang, Y., \&Halvorsen-Ganepola, M. D. K. (2013).A meta-analytic structural model of dispositional affectivity and emotional labor.Personnel Psychology, 66, 47-90.

Liao, H., \& Chuang, A. (2004). A multilevel investigation of factors influencing employee service performance and customer outcomes. Academy of Management Journal, 47(1), 41-58.

Lin, Fan-Ch(2008). D. Towensend. An introduction to Aesthetics, Taipei City : Hsue Fu.

Maquet, J. (1986). The aesthetic experience. New Haven : Yale University

Meglino, B. M., Ravlin, E. C., \& Adkins, C. L. (1989). A work values approach to corporate culture: A field test of the value congruence process and its relationship to individual outcomes. Journal of Applied Psychology, 74, 424-432.

Meglino, B. M., \& Ravlin, E. C. (1998). Individual values in organizations: Concepts, controversies, and research. Journal of Management, 24, 351-389.

Muchinsky, P. M., \&Monohan, C. J. (1987). What is person-environment congruence? Supplementary versus complementary models of fit. Journal of Vocational Behavior, 31, 268-277.

Netemeyer, R. G., Durvasula, S., \& Lichtenstein, D. R. (1991). A cross-national assessment of the reliability and validity of the CETSCALE.Journal of Marketing Research, 28(3), 320-327. fit, job choice decisions, and organizational entry.Organizational Behavior and Human Decision Processes, 67(3), 294-331.

Cao, Q., Gedajlovic, E., \& Zhang, H. (2009). Unpacking organizational ambidexterity: Dimensions, contingencies, and synergistic effects. Organization Science, 20(4), 781-796.

Chao Chian(2002). What is Aesthetics. Taipei City: Yang Che Culture.

Deci, E. L., \& Ryan, R. M. (1985).Intrinsic motivation and self-determination in human behavior. New York: Plenum.

Diefendorff, J. M., \&Gosserand, R. H. (2003).Understanding the emotional labor process: A control theory perspective.Journal of Organizational Behavior, 24(8), 945-959.

Diefendorff, J. M., Croyle, M. H., \&Gosserand, R. H. Nickson, D., Warhurst, C., \& Dutton, E. (2005).The importance of attitude and appearance in the service sector encounter in retail and hospitality. Managing Service Quality. 15(2), 195-208.

Payne, S. C., \& Webber, S. S. (2006). Effects of service provider attitudes and employment status on citizenship behaviors and customers' attitudes and loyalty behavior. Journal of Applied Psychology, 91(2), 365.

Peng Tai Guan\&Kao Yua Tzi\&Lin Tsen Chin(2006). Common Method Variance in Management Research : Problems, Effects, Tests and Rescue. Management Journal, 23(1) , 77-98。

Rafaeli, A., \& Sutton, R. I. (1987). Expression of emotion as part of the work role.Academy of management review, 12(1), 23-37.

Rokeach, M. (1973).The nature of human values. New York: Free

Segers, J., Inceoglu, I., Vloeberghs, D., Bartram, D., \&; Henderickx, E. (2008). Protean and boundaryless careers: A study on potential motivators. Journal of Vocational Behavior, 73(2), 212-230

Schneider, B., White, S. S., \& Paul, M. C. (1998). Linking service climate and customer perceptions of service quality: Tests of a causal model. Journal of applied Psychology, 83(2), 150-163.

Schwartz, S. H., \& Bilsky, W. (1987).The structure and importance of personal values in six societies. Manuscript in preparation.

Taris, R., \& Feij, J. A. (2000). Longitudinal examination of the relationship between supplies-values fit and work outcomes. The 15th annual conference of the Society for Industrial and Organizational Psychology, New Orleans, LA.

Tsun Wei Hsung(2005). Aesthetics Economics : 60 Micro-observation of Taiwan's Socical Evolution. Cayman Islands:CT

Verquer, M. L., Beehr, T. A., \& Wagner, S. H. (2003). A meta-analysis of relations between person-organization fit and work attitudes. Journal of vocational behavior, 63(3), 473-489.

Warhurst, C., Nickson, D., Witz, A., \& Cullen, A. M. (2000). Aesthetic labour in interactive service work: Some case study evidence from the " new " Glasgow. Service Industries Journal, 20(3), 1-18.

Warhurst, C., \& Nickson, D. (2007).Employee experience of aesthetic labour in retail and hospitality.Work Employment Society, 21(1).

Wilk, S. L., \& Moynihan, L. M. (2005). Display rule "regulators": The relationship between supervisors and worker emotional exhaustion. Journal of Psychology, 90(5), 917-927. 